\title{
APENDICITE AGUDA ISQUEMMICA EM COELHOS: UM NOVO MODELO COM ESTUDO HISTOPATOLÓGICO
}

\author{
ACUTE ISCHAEMIC APPENDICITIS IN RABBITS: NEW MODEL WITH \\ HISTOPATHOLOGICALSTUDY
}

\author{
Fernando Costa Nunes, TCBC-MG ${ }^{1}$ \\ Alcino Lázaro da Silva, TCBC-MG²
}

\begin{abstract}
RESUMO: Objetivos: Avaliar a isquemia parcial ou total do apêndice vermiforme de coelhos, através da ligadura com fio inabsorvível dos vasos do meso apêndice bem como a obstrução mecânica, através da ligadura com fio inabsorvível da base do apêndice a $1 \mathrm{~cm}$ do ceco, na patogênese da apendicite aguda. Avaliar a histologia do apêndice (normal e acometido). Estudar a flora bacteriana residente no apêndice vermiforme (normal e acometido) e do exsudato peritoneal. Método: Foram utilizados 72 coelhos (Oryctogalus cuniculos), machos, da linhagem Nova Zelândia, com peso médio de 3.000 gramas. Foram divididos em grupos: piloto (A), flora bacteriana (B), controle $(\mathrm{H})$ e experimento $(\mathrm{C}, \mathrm{D}, \mathrm{E}, \mathrm{F}$ e $\mathrm{G})$ com períodos de observação de 96 horas e 192 horas. Fez-se a ligadura dos vasos do meso apêndice com fío inabsorvível nos grupos (D, E, F e G) e da base do apêndice vermiforme a $1 \mathrm{~cm}$ do ceco, no grupo (C). No grupo experimento (D, E, F e G) foi praticado o modelo isquêmico. No grupo experimento (C) foi realizada a obstrução mecânica e no grupo controle $(\mathrm{H})$ foi feita somente a simulação da cirurgia. Resultados: Ocorreu apendicite aguda no grupo experimento (C,D,E,F, e G). Conclusão: O método utilizado causa apendicite aguda com alterações anatomopatológicas distintas. A bactéria residente encontrada na flora fisiológica do suco entérico do apêndice vermiforme e no exsudato peritoneal foi Escherichia coli.
\end{abstract}

Descritores: Apendicite; Doença aguda; Coelhos; In vitro.

\section{INTRODUÇÃO}

A apendicite aguda ainda é a doença inflamatória abdominal de maior freqüência cirúrgica. Incide em todas as idades porém, acomete principalmente indivíduos jovens em fase produtiva da vida ${ }^{1-3}$. Coube a Reginaldo Fitz, ${ }^{4}$ em 1886, compreender melhor o problema e indicar a operação imediata antes de observar e esperar a perfuração para drenar o conseqüente abscesso. Ainda assim, a apendicite aguda permanece atualmente como uma doença grave, com repercussões gerais de evolução imprevisível. Oferece dificuldades no diagnóstico, na terapêutica adequada e no controle de suas complicações ${ }^{2}$.
Duas teorias etiopatogênicas da apendicite aguda são as mais aceitas: a disseminação bacteriana, levando ao processo inflamatório do apêndice vermiforme $^{5}$ e a da obstrução do lume apendicular desencadeando a estase, hiper - secreção e proliferação bacteriana ${ }^{6-10}$.

Diversos modelos obstrutivos foram criados para desenvolver apendicite aguda sem preocupação, porém, com o acompanhamento anatomopatológico de sua evoluçãoo,7,11-17. Esta informação é de particular interesse, pois as complicações na evolução da apendicite aguda ocorrem paralelamente à gravidade da lesão apendicular. Desta forma, para melhor compreensão de seus mecanismos etiopatogênicos, o

1. Mestre e Doutor, em Cirurgia, UFMG; Professor Adjunto do Departamento de Clínica Cirúrgica da Faculdade de Medicina de Itajubá.

2. Professor Titular de Cirurgia do Aparelho Digestivo, UFMG.

Recebido em 23/10/2002

Aceito para publicação em $21 / 11 / 2003$

Trabalho (doutorado) realizado no Curso de Pós-Graduação em Cirurgia da Universidade Federal de Minas Gerais (UFMG). 
estudo deve ser feito nas fases mais avançadas da doença, quando ocorrem gangrena e perfuração.

Através de apendicostomia, com o apêndice vermiforme lavado e totalmente ligado,observou-se pressões intraluminares crescentes em coelho, chimpanzé e homem. Pressões tão altas quanto $125 \mathrm{~cm}^{3}$ de água foram alcançados no homem depois de $14 \mathrm{~h}$ de ligadura ${ }^{7,14,18}$. Após 9h, as pressões mantidas artificialmente com uma coluna de $10 \mathrm{~cm}^{3}$ de água produziram mudanças inflamatórias ${ }^{14}$.

O fluxo sangüíneo foi observado diretamente na parede do apêndice com o microscópio. Desta forma foi possível confirmar que a pressão intraluminar de $30 \mathrm{~mm} \mathrm{Hg}$ parou o fluxo capilar, a pressão de $60 \mathrm{~mm} \mathrm{Hg}$ interrompeu o fluxo venoso, e finalmente, a pressão de $130 \mathrm{~mm} \mathrm{Hg}$ cessou toda a circulação ${ }^{17}$.

Nossos objetivos são, estudar um novo modelo experimental isquêmico de apendicite aguda e reavaliar o modelo obstrutivo clássico, através da histologia e da flora bacteriana residente, no suco entérico (normal e no acometido) e no exsudato peritoneal.

\section{MÉTODO}

Foi utilizada uma amostra de 72 coelhos Oryctolagus cuniculus, linhagem Nova Zelândia, machos, adultos, mestiços, sadios, com peso médio de $3 \mathrm{~kg}$, distribuídos aleatoriamente em oito grupos:

Grupo A - seis coelhos, para o estudo piloto;

Grupo B - cinco coelhos para o estudo da flora bacteriana residente nas fezes colhidas no interior do apêndice normal.

Grupo C - ligadura com fio de seda 2-0 do apêndice vermiforme a um centímetro do ceco (modelo obstrutivo).

Nos coelhos dos grupos D, E, F, e G o apêndice foi exposto e dividido em três segmentos, de acordo com o seu comprimento e a seguir foi realizada a (isquemia) ligadura dos vasos (artéria e veia), com fio de seda 2-0 segundo cada grupo:

Grupo D- ligadura dos vasos do $1 / 3$ proximal

Grupo E- ligadura dos vasos do $1 / 3$ médio

Grupo F - ligadura dos vasos do $1 / 3$ distal

Grupo $\mathrm{G}$ - ligadura total dos vasos

GRUPO H - (grupo controle) manipulação do apêndice, sem traumatizá-lo, e reintrodução na cavidade abdominal.
Um coelho foi utilizado para o estudo anatômico e histológico normal do apêndice vermiforme e serviu como referência para o nosso estudo.

A experimentação foi realizada nas dependências do Biotério e nos Laboratórios da Técnica Cirúrgica e Cirurgia Experimental, de Histologia, de Patologia ede Análises Clinicas, pertencentes ao Hospital-Escola da Faculdade de Medicina de Itajubá.

Os animais foram manuseados conforme normas do Colégio Brasileiro de Experimentação Animal (COBEA). Foram mantidos no Biotério em gaiolas individuais, com iluminação e aeração naturais, em temperatura ambiente, antes e após a primeira intervenção cirúrgica, sem qualquer restrição alimentar (ração)®. Eles foram identificados com coleiras numeradas. O pré, per e pós-operatórios foram realizados de acordo com protocolos previamente definidos.

A avaliação do experimento foi feita pelo estudo macroscópico da cavidade abdominal, observando-se a presença de aderências, exsudato na cavidade abdominal, peritonite, abscesso, necrose, obstruções e alterações morfológicas do apêndice (distensão ou atrofia com estenose em seu corpo). Fez - se, em seguida, o estudo microscópico (histopatológico) de cada segmento isquemiado de cada grupo.

$\mathrm{O}$ estudo microscópico foi realizado observando-se, oito cortes histológicos transversais do apêndice vermiforme, com cinco milimicra ( $\mathrm{mm})$ de espessura, corados pela hematoxilina-eosina (HE). Foi realizada a mensuração (peso, comprimento, diâmetros máximo e mínimo, espessura da parede e diâmetro do lume) e a descrição macroscópica (aspectos da serosa, da mucosa e do meso). As peças foram clivadas de acordo com a padronização do serviço.

A análise microscópica procurou avaliar a integridade da mucosa, a presença ou não de infiltrado inflamatório da lâmina própria, o infiltrado da camada muscular, a presença de fenômenos vasculares (hemorragia, hiperemia, necrose, neovascularização) na serosa, bem como aderências a órgãos vizinhos, através da presença de fibrose na serosa.

As alterações histopatológicas caracterizaram os diagnósticos de apendicite flegmonosa e gangrenosa. Apêndices diagnosticados como normais, não apresentaram nenhuma alteração da sua arquitetura histológica. 
Foram realizados exames microbiológicos no exsudato peritoneal e nas fezes colhidas do apêndice (bacterioscopia e cultura). $\mathrm{O}$ exsudato inflamatório que estava no tubo de ensaio estéril, foi semeado em meios de culturas destinados ao crescimento e identificação de microorganismos aeróbios Gram - positivos e Gram - negativos.

Para análise dos resultados foram utilizados testes paramétricos. Foi utilizado o teste de Quiquadrado clássico, mas como o número de dados está entre 20 e 40 foi empregado a correção de
Yates e a verificação da igualdade de variâncias, por meio de teste de Fisher. Fixou-se em 0,05 ou $5 \%$ (a 0,05$)$ o nível de rejeição da hipótese de nulidade.

O estudo estatístico foi realizado na Disciplina de Bioestatística da FMIt ${ }^{19}$.

\section{RESULTADOS}

As alterações macroscópicas podem ser avaliadas nas Tabelas 1, 2 e 3 e nas Figuras 1, 2 e 3.

Tabela 1 - Coelhos dos grupos (C, D, E, F e G) segundo a presença de abscesso bloqueado na cavidade abdominal.

\begin{tabular}{ccrrrr}
\hline Período de Avaliação & Grupo & sim & não & total & $(\%)$ de abscesso \\
\hline $3^{\circ} \mathrm{PO}$ & $\mathrm{C}$ & 0 & 10 & 0 & 0 \\
$7^{\mathbf{0}} \mathrm{PO}$ & $\mathrm{D}$ & 10 & 0 & 10 & 100 \\
$7^{\mathbf{0}} \mathrm{PO}$ & $\mathrm{E}$ & 0 & 10 & 0 & 0 \\
$7^{\circ} \mathrm{PO}$ & $\mathrm{F}$ & 0 & 10 & 0 & 0 \\
$7^{\circ} \mathrm{PO}$ & $\mathrm{G}$ & 10 & 0 & 10 & 100 \\
\hline Total & & 20 & 30 & 20 & 40 \\
\hline
\end{tabular}

Teste do Qui-quadrado; $X 2$ clássico $p=0,0000 ; X 2$ Yates $p=0,0001$

Do grupo D em relação aos grupos: C, E, F; Texte exato de Fisher $(n<20): p=0,0000 ; p<0,01$ Altamente Significante.

Do grupo G para os grupos: C, E, F; IDEM, acima.

Entre os grupos $D$ e $G$, não é possível a analise, pois, não há diferenças.

Tabela 2 - Coelhos dos grupos ( $C, D, E, F$ e $G)$ segundo a presença de peritonite difusa na cavidade abdominal.

\begin{tabular}{cccccc}
\hline Período de avaliação & Grupo & sim & não & total & $(\%)$ de peritonite \\
\hline $3^{\text {o }} \mathrm{PO}$ & $\mathrm{C}$ & 8 & 2 & 10 & 80 \\
$7^{\mathbf{0}} \mathrm{PO}$ & $\mathrm{D}$ & 0 & 10 & 10 & 0 \\
$7^{\mathbf{0}} \mathrm{PO}$ & $\mathrm{E}$ & 0 & 10 & 10 & 0 \\
$7^{\mathbf{0}} \mathrm{PO}$ & $\mathrm{F}$ & 0 & 10 & 10 & 0 \\
$7^{\mathbf{0}} \mathrm{PO}$ & $\mathrm{G}$ & 0 & 10 & 10 & 0 \\
\hline Total & & 8 & 42 & 50 & 16 \\
\hline
\end{tabular}

Teste do Qui-quadrado; X 2 clássico $p=0,0003 ;$ X 2 Yates $\quad p=0,0014$.

Do grupo $C$ em relação aos grupos: D, E, F e G; Texte exato de Fisher.

$(n<20): p=0,0004 ; p<0,01$ Altamente Significante. 
Tabela 3 - Coelhos dos grupos ( $C, D, E, F$ e $G)$ segundo a presença de necrose do apêndice vermiforme.

\begin{tabular}{ccrrrr}
\hline Período de avaliação & Grupo & sim & não & total & $(\%)$ de necrose \\
\hline $3^{\circ} \mathrm{PO}$ & $\mathrm{C}$ & 10 & 0 & 10 & 100 \\
$7^{\circ} \mathrm{PO}$ & $\mathrm{D}$ & 10 & 0 & 10 & 100 \\
$7^{\circ} \mathrm{PO}$ & $\mathrm{E}$ & 0 & 10 & 10 & 0 \\
$7^{\circ} \mathrm{PO}$ & $\mathrm{F}$ & 0 & 10 & 10 & 0 \\
$7^{\circ} \mathrm{PO}$ & $\mathrm{G}$ & 10 & 0 & 10 & 100 \\
\hline Total & & 30 & 20 & 50 & 60 \\
\hline
\end{tabular}

Teste do Qui-quadrado; $X 2$ clássico $p=0,0000 ; X 2$ Yates $p=0,0001$.

Do grupo $C$ em relação aos grupos : E, F; Texte exato de Fisher $(n<20): p=0,0000 ; p<0,01$ Altamente Significante.

Do grupo D para os grupos: E, F; IDEM, acima.

Do grupo G para os grupos: E, F; IDEM, acima.

Entre os grupos $C, D e G$, não é possível a analise, pois, não há diferenças.

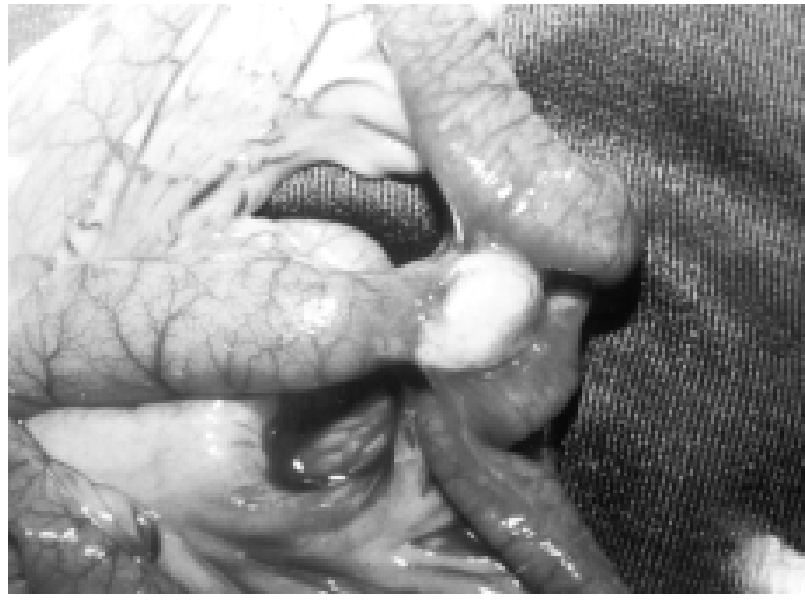

Figura 1 - Abscesso bloqueado pelo intestino delgado no terço distal do apêndice vermiforme.

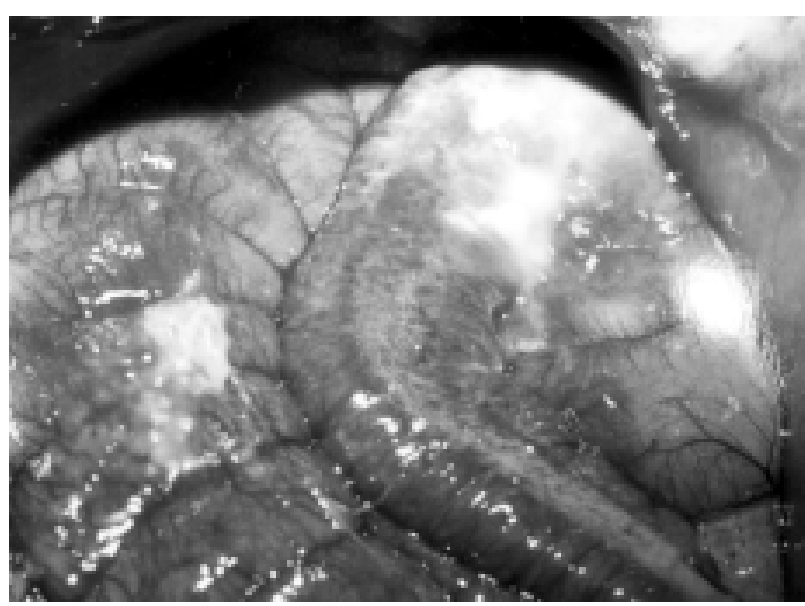

Figura 2 - Peritonite difusa na cavidade abdominal do coelho.

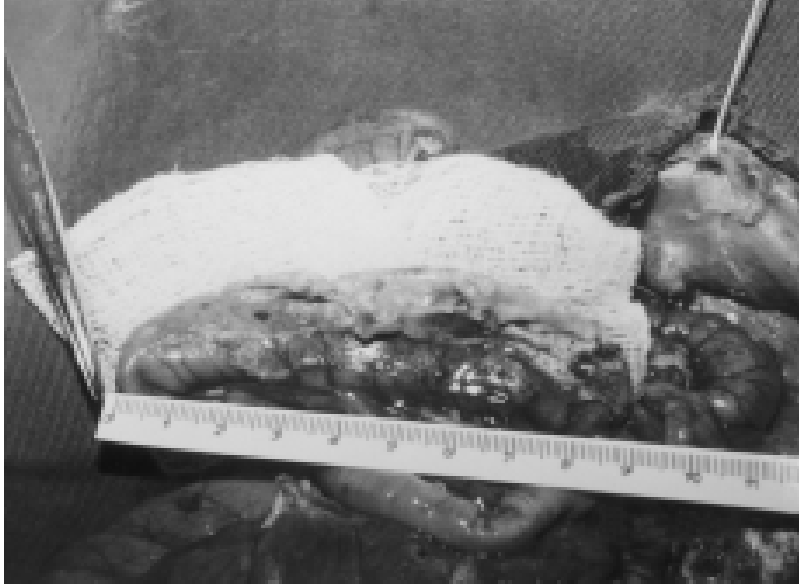

Figura 3 - Presença de necrose do apêndice vermiforme.

As alterações Microscópicas podem ser avaliadas na Tabela 4.

O microorganismo isolado de amostras de material fecal colhido em cinco apêndices vermiformes de coelhos normais, através da bacterioscopia e da cultura, foi E. coli. O mesmo microorganismo foi isolado no exudato peritoneal.

\section{DISCUSSÃO}

Vários animais foram usados experimentalmente no estudo da apendicite aguda ${ }^{6,7,14,20}$. O coelho, entre os animais de experimentação, foi considerado o animal de escolha na pesquisa da apendicite aguda ${ }^{12,14}$. Este apresenta um apêndice com características anatômicas e fisiológicas semelhantes ao do 
Tabela 4 - Coelhos no período de avaliação da apendicite segundo a evolução e o estudo anatomopatológico.

\begin{tabular}{cccccc}
\hline Período de avaliação & Grupo & $\begin{array}{c}\text { Apêndice } \\
\text { normal }\end{array}$ & $\begin{array}{c}\text { Apendicite } \\
\text { supurativa }\end{array}$ & $\begin{array}{c}\text { Apendicite } \\
\text { gangrenosa }\end{array}$ & Total \\
\hline $3^{\circ} \mathrm{PO}$ & $\mathrm{C}$ & 0 & 0 & 10 & 10 \\
$7^{\circ} \mathrm{PO}$ & $\mathrm{D}$ & 0 & 0 & 10 & 10 \\
$7^{\circ} \mathrm{PO}$ & $\mathrm{E}$ & 0 & 10 & 0 & 10 \\
$7^{\circ} \mathrm{PO}$ & $\mathrm{F}$ & 0 & 10 & 0 & 10 \\
$7^{\circ} \mathrm{PO}$ & $\mathrm{G}$ & 0 & 0 & 10 & 10 \\
$7^{\circ} \mathrm{PO}$ & $\mathrm{H}$ & 10 & 0 & 30 & 60 \\
\hline Total & & 10 & 20 & & 10 \\
\hline
\end{tabular}

homem, inclusive com produção de muco, o que facilita o aparecimento de alterações inflamatórias isquêmicas após a obstrução do seu lume ${ }^{14}$ ou da ligadura da sua irrigação.

Além disso, a apendicite aguda espontânea já foi descrita em coelhos ${ }^{21}$.Os modelos experimentais mais adotados, para desenvolver apendicite aguda continuam sendo aqueles que provocam a obstrução irreversível da víscera ${ }^{12}$. Propomos esse novo modelo por acreditarmos que a isquemia venosa e arterial mostram de forma bem mais contundente a destruição das camadas protetoras ou paredes da víscera e por ser o modelo obstrutivo dependente da capacidade secretora da mucosa.

$\mathrm{O}$ modelo isquêmico nos permitiu observar e confirmar, através do estudo histológico, que as aderências e a neoformação vascular permitiram a sobrevida do animal até o $8^{\circ}$ dia do experimento. Ao mesmo tempo que o organismo tentou revascularizar esse segmento isquêmico, gerou bloqueio (plastrão), evitando assim, o extravasamento do suco entérico através de microfístulas para a cavidade peritoneal, e confirmando, assim, os relatos descritos na literatura ${ }^{22,23}$.

Macroscopicamente pudemos observar a presença de atrofia, estenose e distensão (mucocele) por retenção do muco secretado no segmento saudável do apêndice, de acordo com o modelo isquêmico praticado.

A evolução da necrose de víscera oca depois de instalada a isquemia, já foi muito estuda$\mathrm{da}^{24}$. A maioria dos estudos foi realizada com modelos experimentais de isquemia utilizando-se a obstrução arterial ou mista ${ }^{25}$. Em nosso estudo praticamos o modelo misto. Khanna ${ }^{26}$ foi quem primeiro estudou comparativamente a evolução da necrose nas oclusões arteriais e venosas. Seu estudo foi realizado em ratos e demonstrou que a necrose total de parede intestinal ocorria após duas horas de instalação da obstrução venosa, enquanto após a ligadura arterial demorava até oito horas. Szurszewski et a ${ }^{27}$ descreveram que as lesões intestinais secundárias à oclusão venosa evoluem mais rapidamente que as arteriais. Detectaram interrupção da integridade dos feixes musculares (necrose muscular ocorre após quatro horas de isquemia).

Outra consideração importante acerca da necrose se refere ao momento em que ela se torna irreversível. Alguns autores acreditam que a necrose é reversível enquanto não atinge as camadas musculares. Cameron et al ${ }^{24}$ acreditam que o último fenômeno a ocorrer para impedir a reversibilidade da lesão isquêmica é a necrose total da mucosa (completa destruição da barreira mucosa). Confirmamos estes detalhes em cada segmento do apêndice por nos isquemiados, de acordo com cada grupo em nossos experimentos.

Van Zwalenburg ${ }^{28}$ descreveu a teoria do ciclo hidráulico mostrando em órgãos ocos a relação entre a pressão intraluminar e as alterações inflamatórias encontradas. Segundo esse autor, a pressão interferiria na circulação sangüínea da parede do órgão, resultando em necrose e proliferação bacteriana.

Bazzano $^{12}$ em 1996, ao provocar a obstrução da base do apêndice de coelhos por meio da ligadura externa, mostrou a presença de necrose nos grupos de $24 \mathrm{~h}, 48 \mathrm{~h}$ e $72 \mathrm{~h}$ do experimento, diferindo do estudo de Ebram - Neto et a $\mathrm{l}^{29}$ em que a presença de necrose após $24 \mathrm{~h}$ foi de $20 \%$, e em todos os animais após $48 \mathrm{~h}$, evidenciando assim relação entre a necrose e o 
período de 48h. Em nosso modelo obstrutivo pudemos confirmar os achados da literatura, já que no terceiro dia de pós operatório 80 \% dos animais evoluíram para a falência de múltiplos órgãos.

A perfuração do apêndice foi observada a partir de $14 \mathrm{~h}$ de experimento, e só não ocorreu em dois coelhos, do grupo C. A presença de exsudato na cavidade abdominal foi evidenciada em todos, menos nos coelhos do grupo controle. O bloqueio da região apendicular ocorreu, na maioria das vezes, impedindo assim, a contaminação total da cavidade abdominal. Em modelos experimentais, com período de observação de 14 dias , constatou-se nos animais sobreviventes múltiplos abscessos intra-peritoneais bloqueados.

O modelo clássico, obstrutivo, bem como o modelo isquêmico proposto, mostram a ocorrência da apendicite aguda total ou parcial com estenose e hipotrofia parcial ou total do apêndice vermiforme. Confirmamos também a distensão do corpo do apêndice semelhante ao encontrado na maioria dos trabalhos. Esta deve-se a fibroses e a estenoses formadas na mucosa, submucosa, musculares e na serosa, secundária à isquemia local ou segmentar, e que, por sua vez, passa a reter a secreção da camada mucosa, constante de muco apendicular, gerando a mucocele do apêndice vermiforme.

A flora presente nas apendicites é polimicrobiana. Uma associação de germes aeróbios e anaeróbios está presente em um mesmo paciente. As bactérias aeróbias mais comuns são: Escherichia coli, Pseudomonas aeruginosa, Streptococcus do grupo D e Streptococcus viridans. Os germes anaeróbios mais frequientes são: Bacteróides fragilis (73\% dos casos), Bacteróides thetaroto e Peptoestreptococos ${ }^{22}$

Ebram - Neto et al ${ }^{29}$ mostraram o aspecto microscópico evolutivo das alterações inflamatórias do apêndice vermiforme obstruído. No grupo de $12 \mathrm{~h}$ houve apendicite inicial em $60 \%$ dos animais estudados, enquanto que no grupo de $48 \mathrm{~h}$ ocorreu necrose da víscera em todos os animais, deixando evidente que este período é necessário para se produzir de modo uniforme lesões de maior gravidade. O presente modelo experimental, isquêmico, e o modelo obstrutivo clássico permitem o estudo da apendicite aguda nas suas diversas fases evolutivas, pois demonstrou-se haver correlação entre a intensidade das alterações anatomopatológicas e o modelo praticado.

Os nossos resultados, obtidos através do modelo isquêmico, nos permitem admitir a ocorrência de apendicite aguda nas suas diferentes fases evolutivas de forma bem mais contundente que o modelo obstrutivo clássico pois, este é dependente da capacidade secretora da mucosa. E isto foi bem demonstrado por Wangensteen et $a l^{18}$ quando realizaram os seus experimentos em seres humanos, provando que o apêndice vermiforme que apresenta uma mucosa hiposecretante, como nos idosos, mesmo sofrendo obstrução mecânica, não evolui para apendicite aguda. No entanto, quando o processo isquêmico se instala, independente da idade, a necrose, parcial ou total do apêndice vermiforme é irreversível.

\begin{abstract}
Background: To evaluate partial or total ischemia, through ligature with an unabsorbed thread of vessels from the vermiform appendix of rabbits, as well as the mechanical obstruction, through ligature with an unabsorbed thread at the basis of the vermiform appendix, at $1 \mathrm{~cm}$ from the cecum, in the pathogenesis of acute appendicitis. To evaluate the histology of the appendix (normal and affected). To study the resident bacterium flora in the appendix (normal and affected) and the peritonitis exudate. Methods: Seventy- two male rabbits (Oryctogalus cuniculus), from New Zealand lineage were used, weighting approximately 3.000 grams. The animals were divided into: pilot $(A)$, bacterium flora $(B)$, control $(H)$ and experiment $(C, D, E, F$ and $G)$ groups, and were observed in periods of 96 hours and 192 hours. A ligature with an unabsorbed thread of vessels from the meso appendix was performed in group D,E,F,G (ischemic model), and of the base of the appendix, $1 \mathrm{~cm}$ from the cecum, in group $C$ (mechanical obstruction). In the $(H)$ control group only the surgical simulation was performed. Results: Acute appendicitis was detected in experiment group ( $C, D, E, F$ and $G)$. Conclusion: The method used causes acute appendicitis with distinct anatomopathological alterations. The main bacteria found in the physiological flora of the enteric juice of the vermiform appendix and in the exudates peritonitis was Escherichia coli.
\end{abstract}

Key Words: Appendicitis; Acute disease; Rabbits; In vitro. 


\section{REFERÊNCIAS}

1. Pieper R, Kager L, Nasman P - Acute appendicitis: a clinical study of 1018 cases of emergency appendectomy. Acta Chir Scand,1982, 148(1):51-62.

2. Cooperman M-Complications of appendectomy. Surg Clin North Am, 1983, 63(6): 1233-1247.

3. Lázaro Da Silva A, Melo JRC, Guerra JP - Apendicite crônica. Bras Méd, 1970, $27: 73$.

4. Fitz RH - Perforating inflammation of the vermiform appendix, with special reference to its early diagnosis and treatment. Am J Med Sci, 1886, 92:321-346

5. Aschoff L - Ueber die bedeutung des Kotstenine in der aetiologic der epityphitis. Med Klin, 1931, 24:587.

6. Van Zwalenburg C - Obstruction and consequent distention the cause of Appendicitis. JAMA, 1904, 42:820-827

7. Wangensteen $\mathrm{OH}$, Bowers WF - An experimental study of significance of the obstructive factor is the genesis os acute appendicitis. Arch Surg, 1937, 34:496-502.

8. Baussenat M - Appendicitis experimentales. Patogenia de L'appendicite. Thesis, 1897: 2-34.

9. Mcmeans JW - Experimental appendicitis. Arch Intern Med, 1917, 19:709-713.

10. Pieper R, Kager L, Lindberg AA, et al. - Acute appendicitis and Bacteroides fragile. Scand J Infect Dis, 1979, Suppl.19:92-97.

11. Roux P - Appendicitis experimentale. Cong Franc Chir,1895, 8:213.

12. Bazzano FCO - Avaliação dos efeitos da ligadura da base do appendix vermiformis do coelho. Dissertação (Mestrado). São Paulo. Universidade Federal de São Paulo, 1996, 46 p.

13. Tsuji M, Mcmahon G, Reen D, et al. - New insights into the pathogenesis of appendicitis based on immunocytochemical analysis of early immune response. J Pediatr Surg, 1990, 25(4):449-452.

14. Wangensteen $\mathrm{OH}$, Dennis $\mathrm{C}$ - The production of experimental Appendicitis (with rupture) in higher apes by luminal obstruction. Surg Gynecol Obstet, 1940, 70:799806.

15. Welch EL, Navab M - Standardized peritonitis in the rabbit. Dis Colon Rectum,1967, 10(2):125-128.

16. Klecki C - Estude sur la athogénie de la peritonite d" origine intestinales. Estude de la virulence du colibacille. Ann Inst Pasteur, 1895, 9:711-714
17. Van Zwalenburg C - Strangulation resulting from distention of hollow viscera. Ann Surg, 1907, 46:780786.

18. Wangensteen $\mathrm{OH}$, Dennis C - Experimental proof of the obstructive origin of appendicitis in man. Ann Surg, 1939, 110(4):629-642.

19. Arango HG - Bioestatística: teórica e computacional. Guanabara Koogan - Rio de Janeiro, 2001.

20. Bower JO, Burns JC, Mengle HA - Spreading peritonitis complicating acute perforative appendicitis. Experimental studies. Arch Surg, 1938, 37:751-759.

21. Mori M - Spontane appendicitis bei cinigen tierspecies. Mitr Grenzgeb Med Chir, 1903, 12:639.

22. Laufman $\mathrm{H}$ - Gradual occlusion of mesenteric vessels. Experimental study. Surgery, 1943, 13:403-410.

23. Dieulafe R - Contribution a l'etude de l'irrigation de l'intestine grêle-consequence de la ligature ex'perimentale des vaisseaux mésentériques. Arch Anat Histol Embryol, 1936, 21:97-108.

24. Cameron GR, Khanna SD - Regeneration of the intestinal villi after extensive mucosal infarction. J Pathol Bacteriol, 1959, 77:505-510.

25. Mac Fadyen BV, Gliga L, Al-Kaisi NK, et al. Endoscopic and histologic correlates of intestinal ischemia in a canine model. Am Surg, 1988, 54(2): 68-72.

26. Khanna SD - An experimental study of mesenteric ocllusion. J Pathol Bacteriol, 1959, 77:575-590.

27. Szurszewski J, Steggerda FR - The effect of hypoxia on the mechanical activity of the canine small intestine. Am J Dig Dis, 1968, 13(2):178-185.

28. Van Zwalenburg C - Hydraulic vicious circle as it develops in acute appendicitis. Am J Surg, 1932,16:427440.

29. Ebram-Neto J, Celano RMG, Lanzoni VF, et al. - Acute appendicitis: model experimental in rabbits. Arq Gastroenterol, 2000, 37(2):114-119.

Endereço para correspondência:

Fernando Costa Nunes

Rua Geraldo Storino, 98

Porto Velho

37.500-000 - Itajubá - MG

E-mail: fernandocnunes@netfacil.biz 